\title{
Volatile constituents throughout Brassica oleracea L. var. acephala germination
}

\author{
$\underline{\text { F. Fernandes }}{ }^{1}$, D. Gomes ${ }^{1}$, P. Guedes de Pinho ${ }^{1}$, P. Valentão ${ }^{1}$, J. A. Pereira ${ }^{2}$, P. B. \\ Andrade ${ }^{1}$ \\ ${ }^{1}$ REQUIMTE/ Serviço de Farmacognosia, Faculdade de Farmácia, Universidade do Porto, R. Aníbal \\ Cunha, 164, 4050-047 Porto, Portugal \\ ${ }^{2}$ CIMO/Escola Superior Agrária, Instituto Politécnico de Bragança, Campus de Sta. Apolónia, Apartado \\ 1172, 5301-855 Bragança, Portugal
}

Brassicaceae family are commonly grown and consumed worldwide. Belonging to this group, kale (Brassica oleracede var. acephala) is important in traditional farming systems in the Iberian Peninsula. While its seeds have been used for human consumption as oil, or mixed with some food products, sprouts, the germination form, are favoured for their nutritional value [1].

In this work, the volatile composition of kale and its variation along germination was monitored during the first nine days of seedling development, by GC/MS. Qualitative and quantitative differences were found between the materials in the distinct analyzed periods. A total of 70 volatile compounds, distributed by several chemical classes were characterized: alcohols, carbonyl compounds (ketones, aldehydes and esters), norisoprenoids derivatives, terpenes, among others, being sulfur compounds (Fig. 1) the most abundant group in seeds and sprouts. Sprouts with nine days of germination were the richest material in volatile compounds. Comparatively, adult kale leaves was the material with higher content of alcohols and carbonyl compounds and showed lower variety and quantity of sulfur compounds, suggesting that these last can be important for the development of kale while the others are produced mainly during its growth.

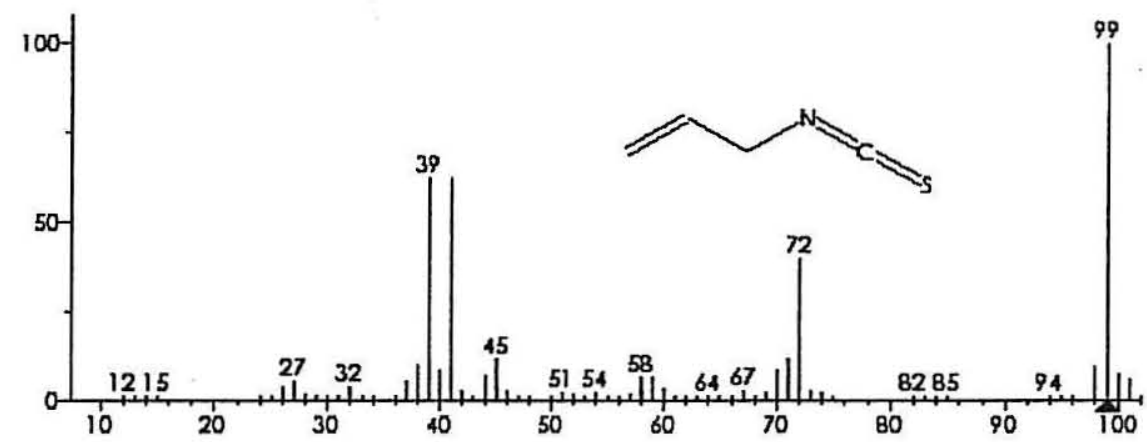

Fig. 1 - MS spectrum of allylisothiocyanate, the most abundant volatile in kale sprouts.

Acknowledgments: To Fundação para a Ciência e Tecnologia for financial support (PTDC/AGRAAM/64150/2006). F. Fernandes (SFRH/BD/37963/2007) and D. Gomes (BI) are grateful to FCT for their grants.

References:

[1] Sousa, C., Lopes, G., Pereira, D., Taveira, M., Valentão P., Seabra, R.M., Pereira, J.A., Baptista P., Ferreres, F. and Andrade, P. (2007), Screening of Antioxidant Compounds During Sprouting of Brassica oleracea L. var. costata, Combinatorial Chemistry \& High Throughput Screening, 10, 377-386. 